\title{
EDITORIAL: THE CORE OF LEADERSHIP
}

Wiley W. Souba, MD, ScD, MBA

A willingness to accept the risk of failure is one of the costs of leadership and, therefore, the price of all success. ${ }^{1}$

- Harold Shapiro

President, Princeton University

Qearch Amazon.com for "leadership" and you will discover more than 5000 entries on the subject, the majority published in the past ten years. One would presume that there must be an unexploited market for these kinds of books if dozens are being printed every month. Does this mean that leadership was not a top organizational priority before 1990? Have we suddenly recognized that leadership is critically important to institutional performance? Not at all.

The key role of leadership in moving an organization forward has been appreciated for many years. What seems to have changed is our understanding of what effective leadership is all about. In the past, good leadership was really good management. The emphasis was on controlling, planning, and predictability. Today, it is becoming increasingly clear that effective leaders spend their time with a different focus-aligning people, motivating them, and creating useful change.

Ask people who have worked at an academic medical center for more than five years if things have changed and they will look at you as though you are from another planet. The amount of turmoil that has pervaded these mammoth institutions in the past several years has been enormous. ${ }^{2,3}$ One of the criticisms directed at academic medical centers is that they have been slow to respond to this rapidly evolving health care environment. This sluggishness may be due in part to ineffective leaders who are still trying to run their enterprises by outdated methods. Some of these people talk about

From the Department of Surgery, Penn State College of Medicine and the Hershey Medical Center, Hershey, Pa.

Received for publication Jan 21, 2000; accepted for publication Jan 21, 2000

Address for reprints: Wiley W. Souba, MD, ScD, MBA, Department of Surgery, H051, Penn State College of Medicine, 500 University Dr, Hershey, PA 17033 (E-mail: wsouba@psghs.edu).

J Thorac Cardiovasc Surg 2000;119:414-9

Copyright $\odot 2000$ by Mosby, Inc.

$0022-5223 / 2000 \$ 12.00+0 \quad \mathbf{1 2 / 1 / 1 0 5 8 0 1}$

doi:10.1067/mtc.2000.105801 how progressive they are when they routinely attempt to block change. Others brag about mission statements that are little more than financial targets, or they boast about how they empower their staff when, in reality, they micromanage them. When highly talented individuals say such things but fail to walk the talk, it is clear that a better understanding is needed of what effective leadership in academic medicine is all about.

\section{What is leadership?}

Ask a room full of leaders to explain what they mean by leadership and no two responses will be exactly the same (Table I). Leadership is difficult to define. It cannot be portrayed by a picture. It is not a discipline that relies on the scientific method. Often a story or powerful narrative best captures its essence. Leadership, at its core, is a very human activity, and qualities like honesty, fairness, and credibility are fundamental and recurrent themes regardless of the leadership situation involved.

I define leadership as the art of instilling in people the desire to strive together to create a better future. Explicit in this definition are several key words. That leadership is an art means that it requires knowledge, effort, and practice. Although the study of leadership is not an exact science and there is no instruction book to follow, the critical ingredients of leadership can be learned-indeed, they have to be learned. Leadership is not a position; it is a collection of practices and behavior. Leaders are not necessarily charismatic and they do not possess special gifts. If there are natural born leaders, I have not met one yet.

Leadership fundamentally involves relationships with people who often have wide-ranging backgrounds and different agendas. Leaders inspire these individuals to want to work collectively, often against resistance, toward a common goal or vision. In leading this effort, leaders are remarkably tolerant of diversity in people. They do not seek to replicate themselves. They focus largely on a person's values and contribution to the greater good.

As change agents, leaders must persuade their followers to make the necessary sacrifices to build a better tomorrow. This role is especially relevant to academic surgeons given the current turbulent health care environment. Change is difficult because it is threatening and painful. Therefore it takes time and commitment 
Table I. Some definitions of leadership

The best leadership frames the organization's mission and values in ways that members find transcendent: the goals of the business are transmuted from the dross of ordinary work into higher goals that are worthy of heroic efforts and even sacrifices. -Judith Bardwick ${ }^{16}$

Leadership defines what the future should look like, aligns people with that vision, and inspires them to make it happen despite the obstacles. -John $\mathrm{Kotter}^{10}$

The first responsibility of a leader is to define reality. The last is to say thank-you. In between, the leader is a servant. - Max de Pree ${ }^{17}$

Leadership is the set of qualities that causes people to follow. -Marshal Loeb, Stephen Kindel ${ }^{11}$

A leader is someone who understands where people are going and stands in front of them. - Ghandi $^{18}$

The most important characteristic of a good leader is the ability to create readiness for change and an understanding of the change processes. -Elaine Rubin ${ }^{19}$

The very highest leader is barely known by men. Then comes the leader they know and love. Then the leader they fear. Then the leader they despise. The leader who does not trust will not be trusted. When actions are performed without unnecessary speech the people say, "We did it ourselves." - Lao $T s u^{20}$

The leader of the future will be one who creates a culture or value system based on principles. -Stephen Covey ${ }^{21}$

and a lot of leadership from a lot of people. The willingness to embrace change and use it to one's advantage can transform the department of surgery in such a way that it performs better for patients, faculty, residents, and staff.

A leadership equation. Much as leadership is awkward to describe, its success is difficult to quantify. How does one know how a leader is doing? One formula ${ }^{4}$ that measures excellence in leadership by linking performance with personal qualities can be represented by the following equation:

Leadership effectiveness $=$ Results $\times$ Personal qualities

Although this formula seems straightforward, it is not as clear-cut as it might seem. How a particular department of surgery defines results will depend, in part, on its goals, culture, and core ideology. While results invariably take into consideration financial performance of the clinical activities, most academic departments also care about the success of the research enterprise and the quality of their educational programs. Here again, it becomes key to define performance. Historically, departments have graded their research programs on the basis of numbers of papers published and/or numbers of grants awarded. Other metrics such as quality, innovation, and career development are also important, ${ }^{5}$ and the extent to which they are valued will influence the assessment of leadership effectiveness.

The personal qualities of a leader are as important as results are in determining leadership effectiveness. ${ }^{4}$ They include the leader's knowledge (what the leader knows), actions (what he or she does), and values (what the leader "is"). Studies that focus on what leaders need to know to succeed demonstrate that they must have experience with setting direction and fostering teamwork, as well as a keen grasp of the competitive environment. Leaders must also be able to turn what they know into action. Leaders have to be able to do many things well: listening, empowering, inspiring, dealing with problems, and visibly recognizing others' accomplishments are among the most important.

Clearly, what leaders know and do is essential, but more critical is what leaders "are." Leaders are the highly visible embodiment of the department's mission and core values. Through their conduct and behavior, they represent the essence of what the organization should stand for. Followers choose leaders who are forward thinking, honest, and fair. These core human values cannot be compromised as the department pursues its goals.

Individuals who score well on qualities but poorly on results are not really leaders. They may have superb interpersonal skills and expertise in certain areas, but poor results translate into ineffective leadership. Some people define results in terms of maintaining the status quo, hoping that they will get high marks on their leadership report card. Such a strategy is never sustainable in the long run. Great leaders do the right thing. They know where the department needs to go, and they move in that direction even if it means a radical departure from the status quo. All the popularity in the world will not cover up a lousy performance for very long. 
Table II. Differences between for-profit entities and academic medical centers

\begin{tabular}{lccc}
\hline Entity & Mission & Means of achieving mission & Primary customer \\
\hline For-profit corporations & Margin (profit) & Sales & Consumers; shareholders \\
Academic medical centers & Patient care, research, education & Margin & Patient \\
\hline
\end{tabular}

At the other extreme are those individuals who get impressive results in terms of achieving goals but lack credibility because they use an autocratic style, exhibit questionable ethical behavior, or fail to build trust. They may be quite productive, but the means by which they get results are unacceptable. They may intimidate people with a command and control style in an attempt to generate more work, but eventually they fail as leaders because they lose the support of their followers.

\section{An approach to leading change}

The leader of the future will define what an academic department of surgery should know, do, and be; harness the faculty to that vision; and inspire them to create the necessary changes to attain the goals and results expressed by the vision, despite the roadblocks and hurdles. This leadership challenge involves four fundamental questions.

Why do we exist? What is the point of what we do? Rather than first asking, "Where should we go and how should we get there?," leaders begin with the question, "What do we stand for and why are we in this business of academic surgery?" The department's mission statement defines purpose and sets direction. It should be short, understandable, and unequivocal. As a concise declaration of what the department is trying to accomplish, it focuses on broad but clear objectives.

Sometimes these goals can be articulated in such a way that the mission is not obvious. "We want to increase our research funding by $25 \%$ " sounds like a clear-cut, unambiguous mission when it really is not. The $25 \%$ goal is a target the department hopes to achieve, but the mission is not defined. A mission statement that focuses on numerical goals rather than on purpose can be confusing because it fails to define the reason the department exists. "Our mission is to provide the highest quality care to our patients and to the members of our community, as well as to improve patient care through teaching and biomedical research," is a much clearer statement of purpose.

Some organizations serve those in power, rather than the mission itself. ${ }^{6}$ When this happens the organization's purpose runs the risk of becoming clouded or misdirected. The chief may ask, "What do I want to do (to achieve my goals)?," rather than asking, "Where does the department need to go (to attain its goals)?" Being mission-based means that key decisions are referred to the mission. The legitimate source of authority is the mission and the goals and ideas put forth in it. The Founding Fathers were not the authority on which the United States had its inception. The Constitution was.

Academic medical centers must keep in mind that their mission is different from that of for-profit entities (Table II). ${ }^{7}$ For-profit organizations exist to make a profit. They do so by selling their products and services. Both consumers and shareholders are key customers. Academic medical centers exist to provide patient care, conduct research, and teach. Some of these goods and services can be allocated in the marketplace on the basis of open competition and some cannot. The activities involved in providing these special goods and services (those that are difficult or impossible to distribute fairly via conventional market methods) are the social missions of academic medical centers. ${ }^{8}$ They encompass physician training, research, and the provision of medical care to the uninsured and underprivileged.

Although the axiom "no margin, no mission" has often been quoted, equally pertinent is the expression, "no mission, no margin." A key leadership responsibility is maintaining the mission focus, linking that mission to a compelling vision, and creating the shared values that will guide the department in its pursuit of that vision.

Where are we today? Before the department can formulate and implement a rational game plan guided by its mission, it needs to know where it is today. It does this by acquiring a thorough understanding of the current state of affairs. The process begins with a survey of both the internal and external environment.

A number of techniques can be used to conduct an internal audit. ${ }^{3}$ The SWOT analysis is commonly used to assess the department's competitiveness by examining its Strengths, Weaknesses, Opportunities, and Threats. The chair can begin the process by conducting an inventory of the department's existing strengths (assets) and weaknesses. Several key questions should 
be asked: What distinct capabilities give our department a unique competitive edge in this region? How easy is it for our competitors to copy these core competencies? What deficiencies and gaps need to be plugged?

The external (industry) environment is governed by a set of forces that determine the nature and degree of competition in the regional marketplace ${ }^{3,9}$ : the threat of new players, the bargaining power of providers, the bargaining power of payers, the threat of substitute services (eg, "surgicenters"), the rivalry among the existing industry players, information systems, and reputation. In general, the department of surgery has minimal control but some influence over these forces. For academic departments of surgery to favorably position themselves in this environment and influence it, the leadership must analyze the environment and learn what factors control it. An understanding of the dynamics of these competitive forces is essential.

Where do we want to go? What do we want to accomplish? With a mission statement in place and a sense of where the department is today, the leadership can begin to ask, "Where do we need to go?" A good department chair does not begin by asking, "What do I want?" Rather, the initial question is, "What does the department need to do to be successful?"

Vision refers to a picture of the future with some implicit or explicit commentary on why people should strive to create that future, which serves three purposes. ${ }^{10}$ First, by clarifying the general direction the department needs to follow, it simplifies countless details. Second, it inspires people to move in that direction, often against resistance, because change is painful. Finally, it helps coordinate the actions of the members of the department efficiently and effectively. A vision paints a picture. It is easy to embrace its message. It is flexible but clear. It uses words that resonate with and matter to a lot of people.

A vision that does not mirror the environment is almost invariably doomed to failure. It would be silly for academic medical centers to craft a vision that revolved around differentiating themselves as the region's low cost provider. For people to buy into and rally behind a vision, it must reflect marketplace realities and mission goals. The vision must be developed with input from multiple stakeholders and must be shared throughout the organization. One of the major reasons that transformation initiatives fall short is the failure of the leadership to develop and/or communicate a practical, appealing vision.

Effective leaders use their knowledge, experience, and wisdom to create a compelling vision, but they also use their imagination. ${ }^{11}$ They draw on powerful narratives to produce images that move people such that they are "brought into the story viscerally and feel that, yes, this is my story; I want to be part of this." 12 Martin Luther King's vision, "I have a dream that my four children will one day live in a nation where they will not be judged by the color of their skin but by the content of their character," was stirring because it went far beyond skin color and character. People were able to imagine a world where their was justice, equality, and peace.

How do we get there? What's the strategy? Strategy is the term used to describe what the department does to get what it wants. It is a plan linked to a series of actions designed to achieve a set of goals. Strategy is about choices, choices that purposefully limit what the department does. In the process, it is crucial to distinguish between mission (what the department of surgery exists to do), strategic objectives (what the department wants to accomplish), limitations (what the department cannot do), and constraints (what it must do to survive).

While the chair and/or division chiefs formulate strategy, the responsibility for implementing the strategy should be delegated to those individuals whom the change initiative will most directly affect. Major transformation programs are rarely successful unless the people on the front lines are empowered to make the necessary changes. Academic medical centers are discovering that they perform best when their leaders spend their time setting direction and inspiring people while delegating the authority and accountability to manage work units to those individuals directly responsible for them. This approach will go a long way in building a sense of ownership and institutional loyalty.

For example, as part of a cost-containment strategy, the senior leadership may target a reduction in length of stay and resource use, but the actual execution of the strategy should be the responsibility of the faculty, residents, nurses, and administrators. Simultaneously, institutional support must be provided so that when goals such as "reduce length of stay by one full day" are established, the infrastructure exists so they can be achieved.

Any strategic plan should be tailored to the level of uncertainty in the external environment and should be tied to measurable goals. ${ }^{13}$ Multiple parties should critique it before it is implemented, and the plan should be constantly monitored and revised as necessary. The resource allocation process should mirror the strategy. When the future is clear, the strategic choices are obvious (eg, the shift of inpatient surgery to the outpatient 


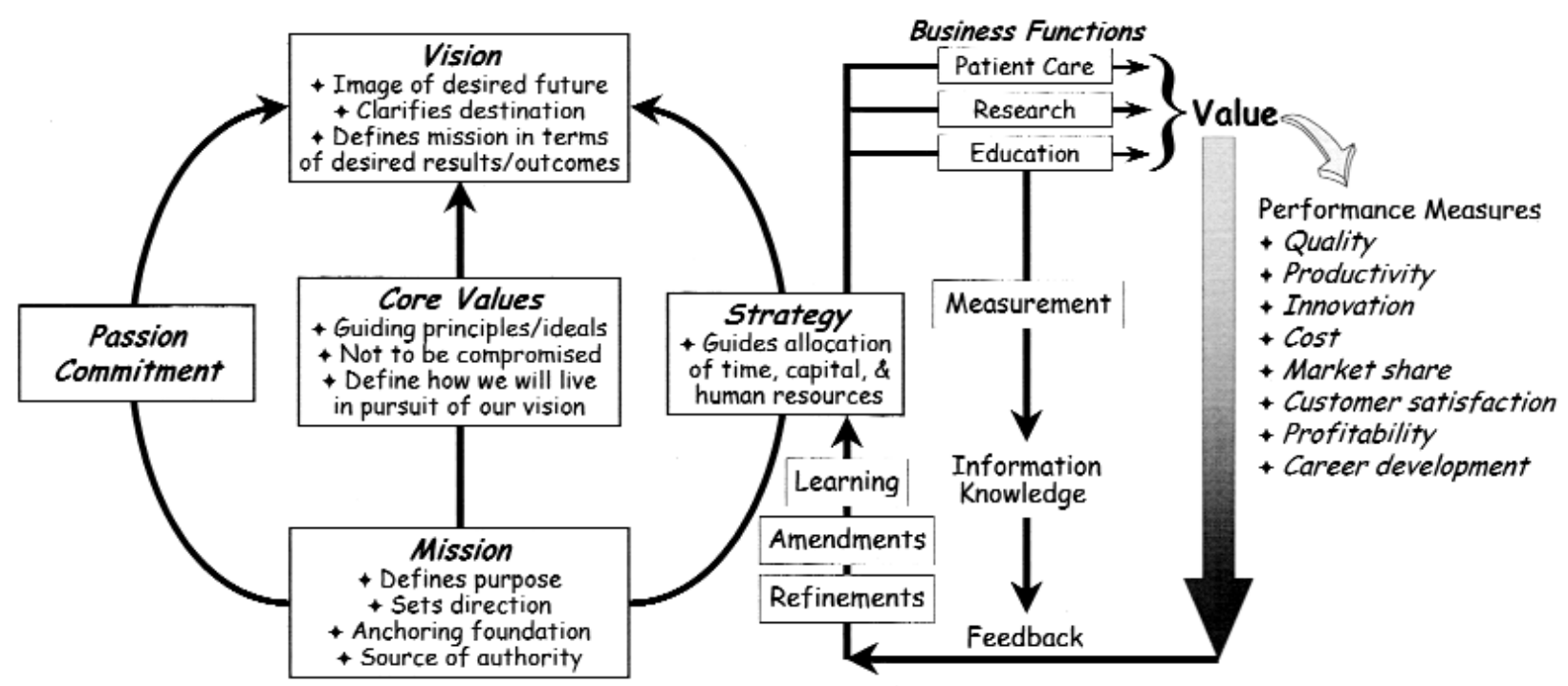

Fig 1. Aligning mission, vision, values, and strategic planning.

setting). When several scenarios are possible (eg, how information technology might affect health care delivery in the next five years), leaders must consider each of these possibilities and build a portfolio of actions ranked by their risk and by their payoff profiles. Finally, when the future is quite uncertain with a whole range of possible outcomes (eg, how international health care alliances will materialize in the next decade), the leader may choose to focus the existing marginal resources on more predictable projects. Dealing with these ambiguities is part of leadership.

Running a department with highly competent individuals but no strategic plan is like performing surgery without a patient on the operating table. There is no way to put the skills to work. Much like customers help the department focus on its vision by aligning its core competencies to execute the strategy, the patient with a specific surgical ailment helps the surgeon provide care by aligning his technical and judgmental skills to perform the proper operation.

A framework for linking mission, vision, values, and strategic planning. Senge ${ }^{6}$ notes that while mission is foundational, it is insufficient in and of itself. We cannot tell how we are doing by examining mission alone. We need a vision and a strategy (Fig 1). Likewise, vision means little without a mission because this purpose instills both the passion and commitment for a difficult journey. Passion and commitment are powerful, but when frustrated they can become dangerous, leading to disenchantment, fragmentation, and isolation. Core values define how the members of the department (and organization) will live in pursuit of the vision.

Strategy links mission to vision by guiding the allocation of time, resources, and people with the goal of improving the department's competitive position in the marketplace. The strategy must focus on results. Its success must be evaluated continuously. Management of risk and uncertainty occurs during all strategic phases, from planning to implementation. Leaders are effective managers of change and risk. Their presence, or lack thereof, is felt primarily when major change is occurring. The leader of any strategic initiative must actively monitor the strategy by building in feedback and improvements. Value created by the clinical, research, and teaching programs must be measured so that revisions in the strategic plan can be made.

\section{Leadership in academic surgery: The force that unifies the troops}

It is becoming increasingly clear that leadership is not just about methods, but about ideas that are visions of a better future that are anchored in basic moral principles and universal values. These standards are inherently powerful for university-based physicians. They give meaning to the work we do. They have their genesis in theology and virtue ethics which, when integrated with the healing arts and the university, serve as the roots that anchor our hospitals and medical schools. ${ }^{7}$ Over time, this foundation gave birth to the social missions of academic medical centers as we know them today (Fig 2). 


\section{Origins/Roots}

+ Spirituality

+ Theology

+ Virtue ethics

+ Healing arts

+ University

\section{Social Missions}

+ Patient care

+ Research

+ Teaching

+ Community service

- Leadership development

Fig 2. The link between the origins and social missions of academic medical centers.

Kouzes and Posner ${ }^{14}$ note that "the first milestone on a journey to leadership credibility is clarity of personal values." Once the principles that will govern our actions are established, they will give purpose to the decisions we make. Leaders who cannot personally adhere to a worthy set of values cannot convince others that those values are worthwhile. Not surprisingly, the leadership qualities most important to followers are honesty and trust. "In essence," says O'Toole, ${ }^{15}$ "the leadership challenge is to provide the glue to cohere independent units in a world characterized by forces of entropy and fragmentation. Only one element has been identified as powerful enough to overcome those centripetal forces, and that is trust. And recent experience shows that such trust emanates from leadership based on shared purpose, shared vision, and especially, shared values." Leaders begin by creating a culture centered on principles and values that resonate with their followers and then inspire them to accomplish their highest aspirations.

\section{REFERENCES}

1. Shapiro, H. The willingness to risk failure. Science 1990;250:609.

2. Souba WW. Reinventing the academic medical center. J Surg Res 1999;81:113-22.

3. Souba WW. How competitive forces mold strategy in academic surgery. Surgery 1999:125:616-29.

4. Ulrich D, Smallwood N, Zenger J. Building your leadership brand. Leader to Leader. Winter 2000;15:40-6.

5. Souba WW, Wilmore DW. Judging surgical research: How should we evaluate performance and measure value? Ann Surg. In press.

6. Senge P. The practice of innovation. Leader to Leader. Summer 1998;14:1-11.

7. Eastwood GL. Leadership amid change: the challenge to acade- mic medical centers. In: Mission management: a new synthesis. Vol 2. Rubin E, editor. Washington [DC]: Association of Academic Health Centers; 1998. pp. 67-84.

8. Blumenthal D, Campbell E, Weissman J. The social missions of academic medical centers. N Engl J Med 1997;337:1550-53.

9. ME Porter. Competitive advantage: creating and sustaining superior performance. New York: Free Press; 1985.

10. Kotter J. Leading change. Boston: Harvard Business School Press; 1996.

11. Loeb M, Kindel S. Leadership for dummies. New York: IDG Books; 1999.

12. Kurtzman J. An interview with Howard Gardner. Strategy \& Business. 1st quarter. McLean [VA]: Booz-Allen \& Hamilton, Inc; 1999. pp. 90-9.

13. Courtney H, Kirkland J, Viguerie P. Strategy under uncertainty. Harvard Business Review. November-December 1997. pp. 67-79.

14. Kouzes JM, Posner BZ. The leadership challenge. San Francisco: Jossey-Bass; 1997.

15. O'Toole J. Leading change: the argument for values-based leadership. San Francisco: Jossey-Bass; 1996.

16. Bardwick J. Peacetime management and wartime leadership. In: The leader of the future. Hesselbein F, Goldsmith M, Beckhard R. San Francisco; Jossey-Bass: 1996.

17. De Pree M. Leadership is an art. New York: Doubleday; 1989.

18. Ghandi. Quoted in: Aschenbrener CA. Leadership, culture, and change: critical elements for transformation. In: Mission management: a new synthesis. Vol 2. Rubin E, editor. Washington [DC]: Association of Academic Health Centers; 1998.

19. Rubin E. Minding the tripartite mission. In: Editors: Bulger R, Osterweis M, Rubin E. Mission management: a new synthesis. Vol 1. Washington [DC]: Association of Academic Health Centers; 1999.

20. Lao Tsu. Quoted in: Pinchot C. Creating organizations with many leaders. In: The leader of the future. Hesselbein F, Goldsmith M, Beckhard R, editors. San Francisco; Jossey-Bass; 1996.

21. Covey SR. Three roles of the leader in the new paradigm. In: The leader of the future. Hesselbein F, Goldsmith M, Beckhard R. San Francisco: Jossey-Bass; 1996. 